International Journal on Electrical Engineering and Informatics - Volume 7, Number 4, Desember 2015

\title{
Optimal Placement and Sizing of DGs in the Distribution System for Loss Minimization and Voltage Stability Improvement using CABC
}

\author{
Mohandas Natarajan, R. Balamurugan and L. Lakshminarasimman \\ Department of Electrical Engineering, Annamalai University, Annamalai Nagar, Tamilnadu, India

\begin{abstract}
This paper presents a chaotic artificial bee colony (CABC) algorithm for optimal placement and sizing of DGs on distribution systems with an aim of reducing the power losses and improving voltage stability. The exploitation ability of solutions to the food searching process is improved in the $\mathrm{CABC}$ algorithm to avoid the premature convergence of an artificial bee colony algorithm. The proposed approach determines the control variable settings such as placement and size of DG for minimization of real power loss with impact of voltage stability in the distribution system. Further, the impacts of DG on the distribution system are studied with an importance on power losses and capacity savings. The proposed approach is examined and tested on 33 bus and 69 bus radial test systems. The simulation results of the proposed approach are compared to earlier reported approaches. The simulation results show the effectiveness of the proposed approach.
\end{abstract}

Keywords: distributed generation, chaotic artificial bee colony, power loss, voltage stability, radial distribution systems.

\section{Introduction}

The function of a distribution system is to deliver electrical power from the transmission network to end users. The distributed generation (DG) is a power source that can be playing an important role in the distribution system in case of power demand. The distribution systems are usually unbalanced and have a high $\mathrm{R} / \mathrm{X}$ ratio compared to transmission systems, which results with the effect of high voltage drops and power losses in the distribution feeders. The vital tasks in the distribution system are reduction of power losses and improvement of the system voltage profile. Many research works have been carried out in this direction since the supporting of analytical and software approach.

The planning of DG handles with the optimal placement and size of DG in the distributed system in order to reduce the real power loss and improve the voltage profile and stability. The impact of real power DG injection into the distribution system for minimizing the power losses and voltage stability has been reported in [1]. The planning methodology used to evaluate any credits the utility might offer if the DG is in an appropriate location to have real benefits for capacity relief [2]. The support an analytical expression used to compute the optimal size and an efficient method to identify the related optimum location for DG placement for reducing the total power losses in primary distribution systems [3]. In [4], the author presented analytical expressions have used to determine the optimum size and power factor of different types of DGs for minimizing power losses in primary distribution systems. The genetic algorithm (GA) based approach to minimize the power loss of the system for evaluated the optimal placement and size of a DG with different loading conditions is reported in [5].

A two-stage methodology of determine the optimal placement and capacity of DGs for loss reduction of distribution systems. The first stage of methodology is used to finding placement and another one is the capacity of DG [6,7]. The power stability index and line losses based for placement and sizing of DG in the distribution system is reported in [8]. The introduction of combined GA and particle swarm optimization (PSO) methods and which is used to calculate the placement and sizing of DG in the distribution system [9]. The loss sensitivity factor (LSF) and simulated annealing (SA) technique are combined and which is used to determine the location and size of DGs in the radial networks [10].

Received: December $3^{\text {rd }}, 2014$. Accepted: October $22^{\text {nd }}, 2015$

DOI: 10.15676/ijeei.2015.7.4.11 
The bacterial foraging optimization (BFO) algorithm based optimal placement and size of DG in the distribution system for considering the real power losses, operational costs and voltage stability [11]. In [12], presents an analysis into the effect of load models on the predicted energy losses of the distribution system in DG planning. A new voltage stability index (VSI) is used to identify the most sensitive node in the radial distribution system with different types of load [13, 14]. The efficient forward and backward propagation based load flow solution technique has been implemented in the radial networks is reported [15].

The artificial bee colony ( $\mathrm{ABC}$ ) algorithm is a population based meta-heuristic approach and which is inspired by intelligent foraging behaviour of honeybee swarm. It is imitates the behaviours of real bees in searching food sources and sharing the information with other bees $[16,17]$. The performance of the ABC is compared with other population based algorithms with the benefit of employing fewer control parameters [18]. The modified versions of ABC algorithm have been introduced in $[19,20]$ and it is used to solving the real-parameter optimization problems.

Most of the earlier reported [9-11], the searching ability of algorithms at starting stage as a global run and end stage as a local run. Therefore, when solving an optimization problem is importance to explore the local optima at an end stage of algorithm run. Moreover, the local searching ability of earlier reported algorithms is less.

In this paper, to encouraging the results in this direction for introducing a chaotic artificial bee colony algorithm is implemented to find the optimal placement and sizing of DGs in the distribution system so as to reduce the real power loss and improve the voltage stability. To improve local optima and avoid premature convergence of the solution, the $\mathrm{ABC}$ algorithm is combined with chaos. The local search capability of the optimization problem is improved using a chaos theory.

\section{Problem formulation}

The objective of the optimal placement and sizing of DGs is to minimize the real power loss in the radial distribution system which can be described as follows,

$$
P_{\text {loss }}=\sum_{i, j \in N L} \frac{P_{i j}^{2}+Q_{i j}^{2}}{\left|V_{i}\right|^{2}} r_{i j}
$$

where,

$\mathrm{P}_{\text {loss }}=$ total system real power loss (MW)

$\mathrm{P}_{\mathrm{ij},} \mathrm{Q}_{\mathrm{ij}}=$ real and reactive power flow in line $\mathrm{i}-\mathrm{j}$

$\mathrm{V}_{\mathrm{i}}=$ voltage at $i^{\text {th }}$ bus

$\mathrm{r}_{\mathrm{ij}}=$ line resistance of $\mathrm{i}-\mathrm{j}$

$\mathrm{NL}=$ number of lines.

While reducing the value of above function is subject to a number of constraints as follows.

\section{A. Power Balance Constraints}

The algebraic sum of the entire receiving power is equal to the sum of entire sending power plus line loss over the complete distribution network and power generated from DG unit.

$$
P_{S S}=\sum_{i=2}^{N B} P_{D}(i)+\sum_{j=1}^{N L} P_{\text {loss }}(j)-\sum_{k=1}^{N D G} P_{D G}(k)
$$

$$
Q_{S S}=\sum_{i=2}^{N B} Q_{D}(i)+\sum_{j=1}^{N L} Q_{\text {loss }}(j)-\sum_{k=1}^{N D G} Q_{D G}(k)
$$


where,

$\mathrm{P}_{\mathrm{D}}$

total system real power demand (MW)

$\mathrm{P}_{\mathrm{DG}}-$ total real power generated by DG (MW)

$\mathrm{Q}_{\mathrm{D}}$ - total system reactive power demand (MVAr)

$\mathrm{Q}_{\text {loss }}$ - total system reactive power loss (MVAr)

$\mathrm{Q}_{\mathrm{DG}}$ - total reactive power generated by DG (MVAr)

NDG - number of DG.

\section{B. DG Real and Reactive Power Generation Limits}

The real and reactive power generation of DG is controlled by its lower and higher limits as follows,

$$
\begin{aligned}
& P_{D G}^{\min } \leq P_{D G} \leq P_{D G}^{\max } \\
& Q_{D G}^{\min } \leq Q_{D G} \leq Q_{D G}^{\max }
\end{aligned}
$$

C. Voltage Profile Limits

The voltage at each node of the radial distribution network is defined as,

$$
V_{i}^{\min } \leq V_{i} \leq V_{i}^{\max }
$$

\section{Line Thermal Limits}

The power carrying capacity of feeders should not exceed the thermal limit of the lines (S).

$$
S_{(i, j)} \leq S_{(i, j)}^{\max }
$$

\section{Types of Distributed Generation}

The DG units are classified into four types in order to deliver the real and reactive power capabilities of the distribution system [4]. In this approach, follow the report [10] for considering that the type 1 (unity p.f) and type 2 (0.866 p.f) DGs only.

\section{A. Type 1 (P inject)}

This type of DG (e.g., Photovoltaic, fuel cells and micro turbines) is having the capacity of delivering the real power only and operates at unity power factor.

$$
P_{i}=P_{D G i}-P_{D i}
$$

where,

$P_{i}$ is the net real power of node $i$

$P_{D G i}$ is the real power injected at node $i$

$P_{D i}$ is the real power demand of node $i$.

B. Type $2(P Q$ inject)

In this type of DG (e.g., synchronous generator) is having the capacity of delivering both real and reactive power. The power factor of DG is fixed at 0.866 leading. By considering $a=$ (sign) $\tan \left(\cos ^{-1}(P F)\right)$ as in [4], the reactive power output of DG is expressed as,

$$
Q_{D G i}=a P_{D G i}
$$

In this type, $a=(+1) \tan \left(\cos ^{-1}\left(P F_{D G}\right)\right)$

$$
Q_{i}=Q_{D G i}-Q_{D i}
$$

where,

$Q_{i}$ is the net reactive power of node $i$ 
$Q_{D G i}$ is the reactive power based DG of node $i$

$Q_{D i}$ is the reactive power demand of node $i$.

In which,

sign $=+1$; DG supplying reactive power.

sign $=-1$; DG absorbing reactive power.

$\mathrm{PF}_{\mathrm{DG}}=$ Power Factor of DG.

\section{Effect of DG on Voltage Stability}

The impact of DG in the distribution system is to increasing the real power loading capacity of the system which related to the voltage stability. The voltage stability index (VSI) gives the information for voltage stability of the radial distribution systems. The variation of this factor which indicating system voltage stability in presence and absence of DGs. The VSI is defined as [13],

$$
V S I(m 2)=|V(m 1)|^{4}-4.0\{P(m 2) x(j j)-Q(m 2) r(j j)\}^{2}-4.0\{P(m 2) r(j j)+Q(m 2) x(j j)\}|V(m 1)|^{2}
$$

where,

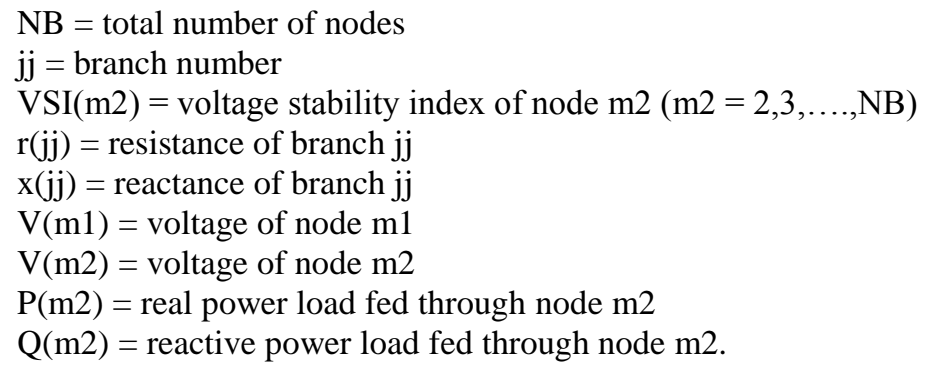

The evaluated value of VSI is greater than zero, which indicating system operates in stable condition, otherwise system goes to instability.

\section{An overview of artificial bee colony algorithm}

The $\mathrm{ABC}$ algorithm is an optimization algorithm that simulates the behaviour of honey bees. In the $\mathrm{ABC}$ algorithm, the colony of artificial bees can be classified in to three sets, such as employed, onlookers and scouts. The bees are searching with specific food sources are named as employed bees. The onlooker bees are waiting on the dance area for making the decision to choose a food source. The bees are search for food sources randomly called scouts. The main steps of the $\mathrm{ABC}$ algorithm are explained as follows,

Step 1 : Initialize the random population of food source, limit and maximum cycle number. Step 2 : Implement the employed bee procedure to adjust the food source of function and calculate the corresponding fitness function.

Step 3 : Adjust the food source based on onlooker bee procedure and calculate the corresponding fitness function.

Step 4 : The specific food source solution is abandoned, which is replaced by sending the scout bee procedure.

Step 5 : Update the cycle.

The number of cycle reaches at maximum cycle number (MCN) of the algorithm, print the finest results of the optimization problem. 


\section{A. Chaotic local search}

The chaos theory is used to develop the searching behaviour and to avoid the premature convergence of solutions in the optimization problem. The chaotic local search considers as a two well known maps such as logistic map and tent map. The chaotic local search can be described as the following logistic equation as,

$$
\begin{aligned}
& c x_{i}^{k+1}=4 c x_{i}^{k}\left(1-c x_{i}^{k}\right) \\
& i=1,2, \ldots, n
\end{aligned}
$$

where, $c x_{i}$ is the $i^{\text {th }}$ chaotic variable, and $k$ is the maximum number of iterations or 300 . The chaotic local search has the following procedure.

The decision variables $x_{i}^{k}$ is converted into chaotic variables $c x_{i}^{k}$ using the equation

$$
c x_{i}^{k}=\frac{x_{i}^{k}-l b_{i}}{u b_{i}-l b_{i}} \quad i=1,2, \ldots ., n
$$

where, $l b_{i}$ and $u b_{i}$ are the lower and upper bound of the $x$.

Calculate the chaotic variables $c x_{i}^{k+1}$ using the equation (12) for the next iteration.

The chaotic variables $c x_{i}^{k+1}$ is converted into decision variables $x_{i}^{k+1}$ using the following equation

$$
x_{i}^{k+1}=l b_{i}+c x_{i}^{k+1}\left(u b_{i}-l b_{i}\right) \quad i=1,2, \ldots \ldots, n
$$

Calculate the new solution with decision variables $x_{i}^{k+1}$.

Revise the recent solution of the problem if it has improved fitness when compared to previous one.

\section{B. Chaotic Artificial Bee Colony algorithm}

The ABC algorithm is used to update the food source of the bees and which is combined with chaos theory is called CABC. In order to combinations of this algorithm has improved the exploitation process of the searching food source in the optimization problem. The CABC algorithm is used as the less number of control parameters. The CABC algorithm has the following steps:

Step 1: Initialize the random population, limit, $k$ and $\mathrm{MCN}$.

Step 2: Generate the initial population $x_{m i}$ using the equation as,

$$
x_{m i}=l b_{i}+\operatorname{rand}[0,1] *\left(u b_{i}-l b_{i}\right)
$$

Step 3: Set the cycle $=1$.

Step 4: Send the employed bee procedure to adjust the food source $\vec{v}_{m}$ using the equation as,

$$
v_{m i}=x_{m i}+\operatorname{rand}[-1,1] *\left(x_{m i}-x_{k i}\right)
$$

where, $x_{k}$ is a randomly selected food source, $i$ is a randomly chosen parameter index. Calculate the fitness value of food source. If the new food source vector has better fitness value than older one, it replaces the old. 
Step 5: Send the onlooker bee procedure to adjust the food source $\vec{v}_{m}$ using the probability of equation (17) and (16).

$$
p_{m}=\frac{\text { fit }\left(\vec{x}_{m}\right)}{\sum_{m=1}^{S N} \text { fit }\left(\vec{x}_{m}\right)}
$$

where, $S N$ denotes the size of onlooker bees. Calculate the fitness value of corresponding food source. If the new food source vector has better fitness value than older one, it replaces the old.

Step 6: Send the chaos theory procedure to adjust the food source $\vec{x}_{i}$ using the equation (12), (13) and (14). Evaluate the fitness value of related food source. Apply the greedy selection with the purpose of find the best food source vector of the problem.

Step 7: If there is any specific food source solutions are abandoned, and it will be replaced by a new randomly produced solution $v_{m}$ for the scout bee using the equation (15).

Step 8: Memorize the finest food source position achieved so far.

Step 9: Cycle $=$ Cycle +1 .

Step 10: If the number of cycle attains at MCN, Print the finest result of the problem.

\section{Implementation of $C A B C$ algorithm to optimize the objective function}

The proposed $\mathrm{CABC}$ algorithm is developed and executed using the MATLAB software. The first important aspect of this algorithm is to assign the colony size $(\mathrm{CS})=50$, limit $(\mathrm{L})=$ $(\mathrm{CS} * \mathrm{D}) / 2, k=300$ and $\mathrm{MCN}=200$ of the problem. The CABC algorithm starts by creating the initial random population of the possible food source solutions. In this approach, the placement and sizing of DGs in the distribution system are considered as variable parameters in order to optimize the problem. The placement of DG is represented as the integer variable of the problem. In this connection with $\mathrm{CABC}$ algorithm can be reformulated by rounding off the food source position to the nearest integer.

Set the number of cycles and then send the employed bee procedure in order to produce the new solution. Further, to apply the greedy selection between current solution and it's disturbing. Calculate the probability of the solution and send the onlooker bee procedure to adjust the solution. Send the chaos theory procedure is to improve the exploitation process of searching the new food source solution. To apply the greedy selection process for both ends of onlookers and chaos theory procedures of the problem. The specific food source solutions are abandoned by applying the scout bee procedure to produce the new food source solutions. The generating random populations are within limits and satisfied the above mentioned constraints. If the number of cycles reaches at maximum, the algorithm which it will be stop and gives the optimal (or near optimal) value of placement and sizing of DGs in the test systems.

\section{Simulation results}

To validate the effectiveness and robustness of the proposed CABC algorithm based optimal placement and sizing of DG approach has been tested on using 33-bus and 69-bus radial distribution systems. The base values used are $100 \mathrm{MVA}$ and $12.66 \mathrm{KV}$ for both the test systems. The load and line data of the 33-bus system is taken from the reference [22] and 69bus system is given in appendix. The main objective of this approach is to reducing the real power loss and improving voltage stability of the test systems with satisfied constraints. Three DG units are optimally placed and sized of the test systems. To express the superiority of this proposed $\mathrm{CABC}$ approach has a simulation results have been compared with various algorithm results in the report, such as genetic algorithm (GA), particle swarm optimization (PSO), GA/PSO in [9], simulated annealing (SA) in [10] and bacterial foraging optimization (BFO) in [11]. 


\section{A. 33-bus radial system}

The table 1 shows the results of real power loss, voltage stability index, optimal placement and sizing of the DGs of the system are obtained by different methods. These results confirm that the CABC approach to obtain the minimum real power loss is $0.07279 \mathrm{MW}$ (type 1) and 0.01535 MW (type 2) when compared to other methods. Resultant that the real power loss is reduced to $65.50 \%$ (type 1) and $92.72 \%$ (type 2) compared to base case condition. For the reduction of real power loss has greatly improved the voltage profile and performance of the system. The graphical representation of the VSI of each node (except substation) of the system is shown in figure 1 . The minimum value of VSI is 0.8805 (type 1) and 0.9688 (type 2) of this approach greatly improved when compared to the absence of DG in the system.

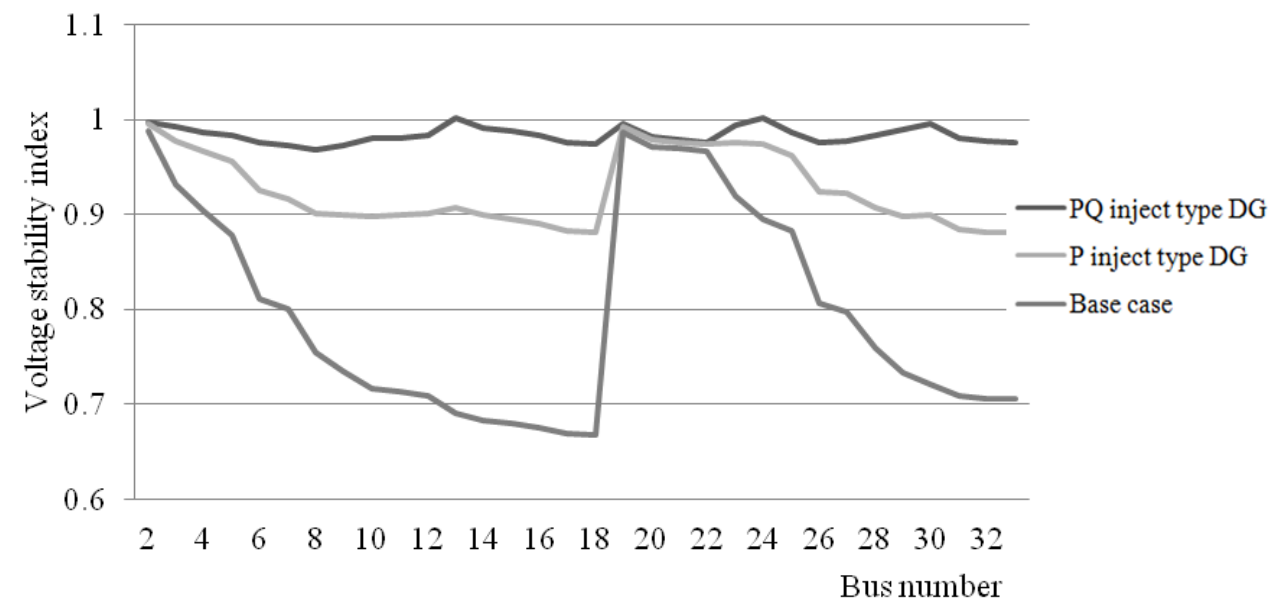

Figure 1. Voltage stability index of 33-bus radial system

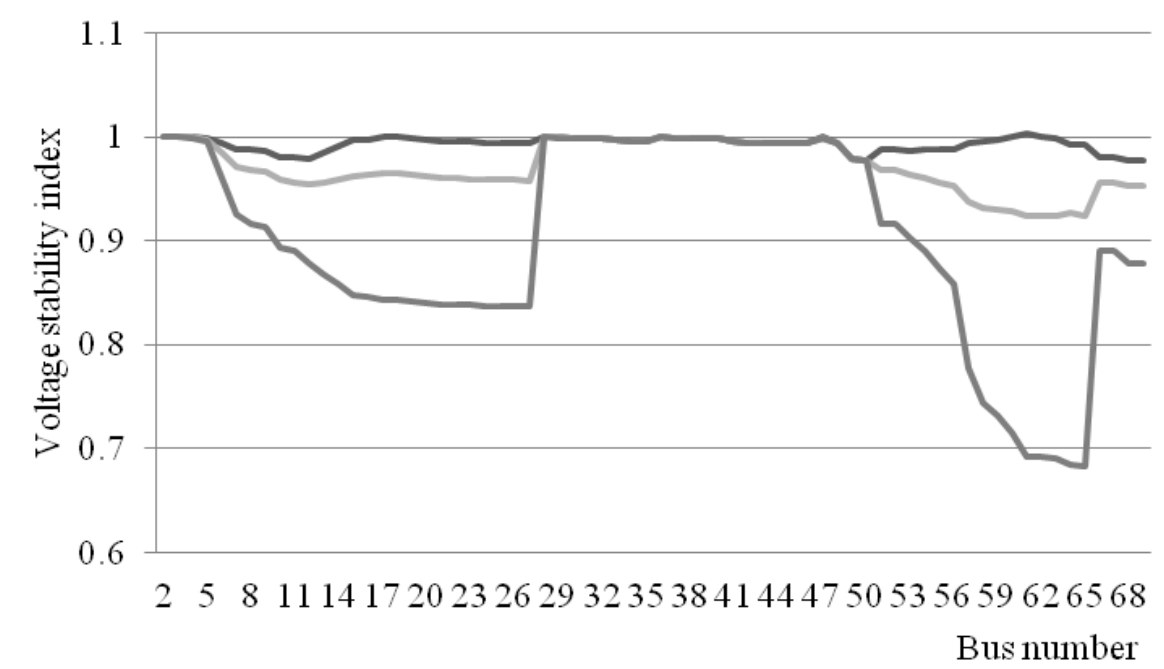

Figure 1. Voltage stability index of 69-bus radial system

\section{B. 69-bus radial system}

The table 2 shows the results of real power loss, voltage stability index, optimal placement and sizing of the DGs of the system are evaluated by different methods. In this system, the real power loss has come down to $0.07159 \mathrm{MW}$ (type 1) and $0.00874 \mathrm{MW}$ (type 2) or $68.18 \%$ (type 1) and $96.12 \%$ (type 2) when compared to other methods. The minimum VSI of this system is 0.9234 (type 1) and 0.9772 (type 2) and it is value of each node as shown in figure 2. 
Mohandas Natarajan, et al.

Table 1. The performance analysis of 33-bus radial system with DGs at different power factors

\begin{tabular}{|c|c|c|c|c|c|c|}
\hline \multirow{2}{*}{ Method } & \multirow{2}{*}{$\mathbf{P}_{\text {loss }}(\mathbf{M W})$} & \multirow{2}{*}{$\mathbf{V S I}_{\text {min }}$} & \multirow{2}{*}{ Bus no. } & \multicolumn{2}{|c|}{ DG $_{\text {size }}$} & \multirow{2}{*}{ Power factor } \\
\hline & & & & $\mathbf{P}_{\mathrm{DG}}(\mathrm{MW})$ & $\mathrm{Q}_{\mathrm{DG}}$ (MVAr) & \\
\hline \multirow[t]{2}{*}{ Base case } & 0.21099 & 0.6672 & - & - & - & - \\
\hline & \multirow{4}{*}{0.10630} & \multirow{4}{*}{0.9258} & 11 & 1.5000 & 0.0 & \multirow{4}{*}{ Unity } \\
\hline \multirow{3}{*}{ GA [9] } & & & 29 & 0.4228 & 0.0 & \\
\hline & & & 30 & 1.0714 & 0.0 & \\
\hline & & & 8 & 1.1768 & 0.0 & \\
\hline \multirow{3}{*}{ PSO [9] } & \multirow{3}{*}{0.10535} & \multirow{3}{*}{0.9247} & 13 & 0.9816 & 0.0 & \multirow{3}{*}{ Unity } \\
\hline & & & 32 & 0.8297 & 0.0 & \\
\hline & & & 11 & 0.9250 & 0.0 & \\
\hline \multirow{3}{*}{ GA/PSO [9] } & \multirow{3}{*}{0.10340} & \multirow{3}{*}{0.9254} & 16 & 0.8630 & 0.0 & \multirow[t]{3}{*}{ Unity } \\
\hline & & & 32 & 1.2000 & 0.0 & \\
\hline & & & 6 & 1.1124 & 0.0 & \\
\hline \multirow{3}{*}{ LSFSA [10] } & \multirow{3}{*}{0.08203} & \multirow[t]{3}{*}{0.8768} & 18 & 0.4874 & 0.0 & \multirow{3}{*}{ Unity } \\
\hline & & & 30 & 0.8679 & 0.0 & \\
\hline & & & 14 & 0.6521 & 0.0 & \\
\hline \multirow{3}{*}{ BFOA [11] } & \multirow{3}{*}{0.08990} & \multirow{3}{*}{0.8868} & 18 & 0.1984 & 0.0 & \multirow{3}{*}{ Unity } \\
\hline & & & 32 & 1.0672 & 0.0 & \\
\hline & & & 13 & 0.8017 & 0.0 & \\
\hline \multirow{3}{*}{ САBC } & \multirow[t]{3}{*}{0.07279} & \multirow[t]{3}{*}{0.8805} & 24 & 1.0913 & 0.0 & \multirow{3}{*}{ Unity } \\
\hline & & & 30 & 1.0537 & $\mathbf{0 . 0}$ & \\
\hline & & & 6 & 1.1976 & 0.6915 & \\
\hline I SFSA & 0.02672 & 0.9323 & 18 & 0.4778 & 0.2759 & 0866 \\
\hline LSFSA [10] & & & 30 & 0.9205 & 0.5315 & 0.806 \\
\hline & & & 14 & 0.6798 & 0.3925 & \\
\hline & 0.03785 & 0.9199 & 18 & 0.1302 & 0.0752 & \\
\hline BFOA [11] & & & 32 & 1.1085 & 0.6400 & 0.866 \\
\hline & & & 13 & 0.7616 & 0.4398 & \\
\hline $\mathrm{CABC}$ & 001535 & 0.9688 & 24 & 1.0304 & 0.5950 & 0966 \\
\hline CADC & 0.01505 & 0.9000 & 30 & 1.2000 & 0.6929 & 0.0000 \\
\hline
\end{tabular}

Table 2. The performance analysis of 69-bus radial system with DGs at different power factors

\begin{tabular}{|c|c|c|c|c|c|c|}
\hline \multirow{2}{*}{ Method } & \multirow{2}{*}{$\mathbf{P}_{\text {loss }}(\mathrm{MW})$} & \multirow{2}{*}{$\mathbf{V S I}_{\text {min }}$} & \multirow{2}{*}{ Bus no. } & \multicolumn{2}{|c|}{ DG $_{\text {size }}$} & \multirow{2}{*}{ Power factor } \\
\hline & & & & $\mathbf{P}_{\mathrm{DG}}(\mathrm{MW})$ & $\mathbf{Q}_{\mathrm{DG}}$ (MVAr) & \\
\hline \multirow[t]{2}{*}{ Base case } & 0.22497 & 0.6833 & - & - & - & - \\
\hline & & & 21 & 0.9297 & 0.0 & \multirow{4}{*}{ Unity } \\
\hline \multirow{3}{*}{ GA [9] } & 0.08900 & 0.9736 & 62 & 1.0752 & 0.0 & \\
\hline & & & 64 & 0.9925 & 0.0 & \\
\hline & & & 17 & 0.9925 & 0.0 & \\
\hline \multirow{3}{*}{ PSO [9] } & 0.08320 & 0.9609 & 61 & 1.1998 & 0.0 & \multirow{3}{*}{ Unity } \\
\hline & & & 63 & 0.7956 & 0.0 & \\
\hline & & & 21 & 0.9105 & 0.0 & \\
\hline \multirow{3}{*}{ GA/PSO [9] } & 0.08110 & 0.9703 & 61 & 1.1926 & 0.0 & \multirow[t]{3}{*}{ Unity } \\
\hline & & & 63 & 0.8849 & 0.0 & \\
\hline & & & 18 & 0.4204 & 0.0 & \\
\hline \multirow{3}{*}{ LSFSA [10] } & 0.07710 & 0.9655 & 60 & 1.3311 & 0.0 & \multirow{3}{*}{ Unity } \\
\hline & & & 65 & 0.4298 & 0.0 & \\
\hline & & & 27 & 0.2954 & 0.0 & \\
\hline \multirow{3}{*}{ BFOA [11] } & 0.07523 & 0.9254 & 61 & 1.3451 & 0.0 & \multirow{3}{*}{ Unity } \\
\hline & & & 65 & 0.4476 & 0.0 & \\
\hline & & & 17 & 0.5381 & 0.0 & \\
\hline \multirow{3}{*}{ CABC } & 0.07159 & 0.9234 & 61 & 1.2000 & 0.0 & \multirow{3}{*}{ Unity } \\
\hline & & & 64 & 0.5350 & 0.0 & \\
\hline & & & 18 & 0.5498 & 0.3175 & \\
\hline \multirow{3}{*}{ LSFSA [10] } & & 0.9678 & 60 & 1.1954 & 0.8635 & \multirow{3}{*}{0.866} \\
\hline & 0.01020 & & 65 & 0.3122 & 0.1803 & \\
\hline & & & 27 & 0.3781 & 0.2183 & \\
\hline \multirow{3}{*}{ BFOA [11] } & 0.01825 & 0.9366 & 61 & 1.3361 & 0.7715 & \multirow{3}{*}{0.866} \\
\hline & & & 65 & 0.3285 & 0.1897 & \\
\hline & & & 17 & 0.5458 & 0.3152 & \\
\hline \multirow{2}{*}{ CABC } & 0.00874 & 0.9772 & 61 & 1.2000 & 0.6929 & \multirow{2}{*}{0.866} \\
\hline & & & 62 & 0.6332 & 0.3656 & \\
\hline
\end{tabular}


The tables $1 \& 2$ show the minimum real power loss of the test systems determined by the different methods. It is clear that the proposed CABC approach has better performance when compared to existing techniques. As a result of this confirms that the CABC is well capable of exploitation process of the solution.

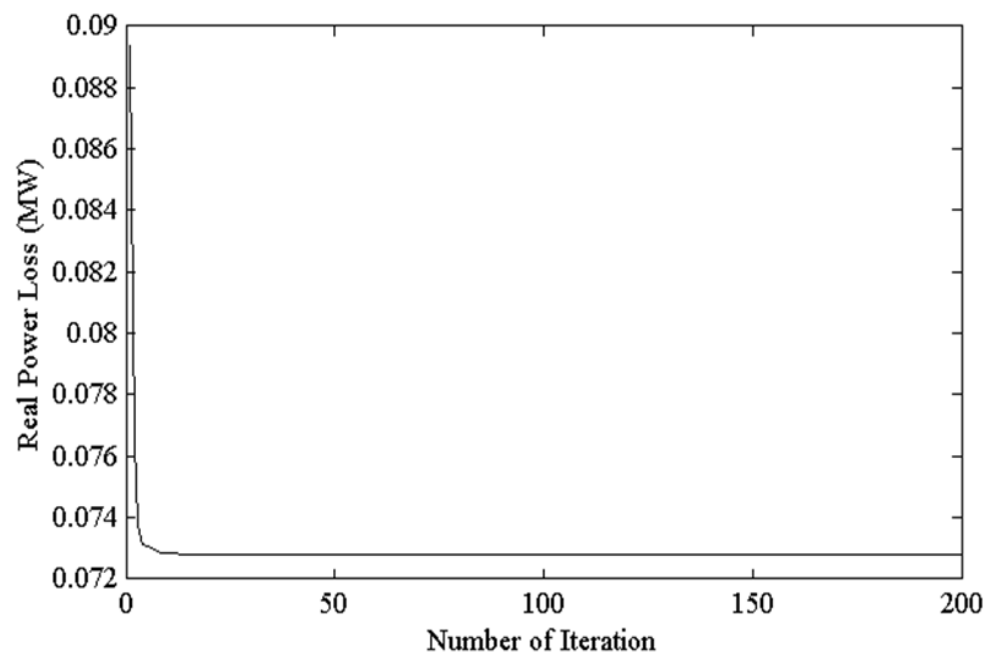

Figure 3a. Convergence characteristics of 33-bus radial system

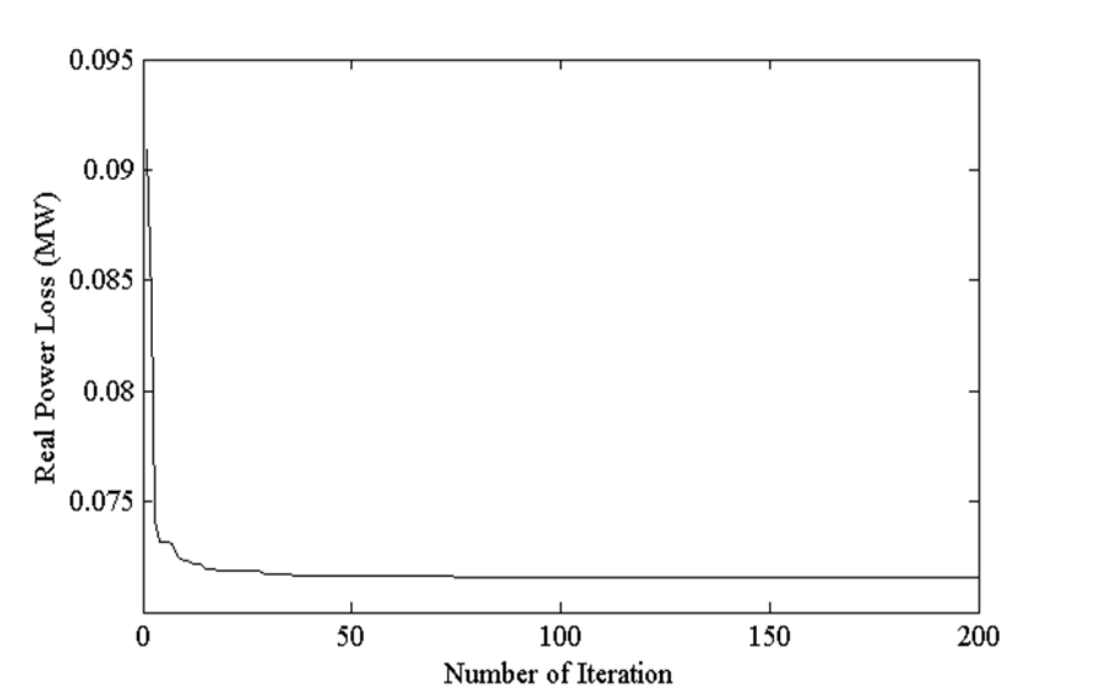

Figure 3 b. Convergence characteristics of 69 -bus radial system

The figures $1 \& 2$ show the voltage stability index of each node of the test systems which represent the real power DG type is better performance when compared to the base case and real $(\mathrm{P})$ and reactive $(\mathrm{Q})$ power inject type $\mathrm{DG}$ much better performance when compared to the above type. The figure $3(\mathrm{a} \& \mathrm{~b}$ ) gives the convergence characteristics of the $\mathrm{CABC}$ algorithm in terms of real power loss and in which to get the best optimal solution for minimum number of cycles. The convergence curves are presented that the real power DG type. Moreover, the combination of real and reactive power inject DG type is also approximately similar to the convergence characteristics of real power DG with reasonable computational time. 


\section{Conclusion}

The CABC algorithm has been developed for the determination of optimal placement and sizing of DGs in the test systems. It has been successfully implemented to the 33-bus and 69bus systems for the minimization of real power loss and to improved system voltage stability. Two different types of DG units are separately placed and sized in the test systems for minimization of real power loss. The graphical representation of VSI results shows that the system voltage stability is potentially improved when the presence of DG. The comparison of simulation results with earlier reported methods in the literature demonstrates the superiority of the proposed algorithm to solve the real power loss minimization of the test systems. The proposed algorithm can be implemented for the solution of the large scale system.

\section{References}

[1]. H. Hedayati, S. A. Nabaviniaki, and A. Akbarimajd, "A Method for Placement of DG Units in Distribution Networks", IEEE Trans., Power Del., vol. 23, no. 3, pp. 1620-1628, July 2008.

[2]. R. C. Dugan, T. E. McDermott, and G. J. Ball, "Planning for distributed generation," IEEE Ind. Appl. Mag., vol. 7, no. 2, pp. 80-88, Mar-Apr.2001.

[3]. N. Acharya, P. Mahat, and N. Mithulananthan, "An analytical approach for DG allocation in primary distribution network", Electrical Power and Energy Systems 28, pp. 669-678, 2006.

[4]. D. Q. Hung, N. Mithulananthan, and R. C. Bansal, "Analytical Expressions for DG Allocation in Primary Distribution Networks", IEEE Trans. On energy Con., vol. 25, no. 3, pp. 814-820, Sep. 2010.

[5]. D. Singh, D. Singh, and K. S. Verma, "GA based Optimal Sizing \& Placement of Distributed Generation for Loss Minimization", World Acad., Sci, Engg., and Tech., vol. 1, pp. 93-99, 2007.

[6]. M. P. Lalitha, V. C. V. Reddy, V. Usha, and N. S. Reddy, "Application of fuzzy and PSO for DG placement for minimum loss in radial distribution system", ARPN Jour., of Engg., and Applied Scies., vol. 5, no. 4, pp. 30-37, Apr 2010.

[7]. M. P. Lalitha, V. C. V. Reddy, and N. S. Reddy, "Application of fuzzy and ABC for DG placement for minimum loss in radial distribution system”, Iranian Journal of Elect., \& Electronic Engg., vol. 6, no. 4, pp. 248-256, Dec. 2010.

[8]. M. M. Aman, G. B. Jasmon, H. Mokhlis, and A. H. A. Bakar, "Optimal placement and sizing of a DG based on a new power stability index and line losses", Electrical Power and Energy Systems 43, pp. 1296-1304, 2012.

[9]. M. H. Moradi, and M. Abedini, "A combination of genetic algorithm and particle swarm optimization for optimal DG location and sizing in distribution systems", Electrical Power and Energy Systems 34, pp. 66-74, 2012.

[10]. S. K. Injeti, and N. P. Kumar, "A novel approach to identify access point and capacity of multiple DGs in a small, medium and large scale radial distribution systems", Electrical Power and Energy Systems 45, pp. 142-151, 2013.

[11]. A. M. Imran, and M. Kowsalya, "Optimal size and siting of multiple distributed generators in distribution system using bacterial foraging optimization", Swarm and Evolut., Compt., 15 pp. 58-65, 2014.

[12]. K. Qian, C. Zhou, M. Allan, and Y. Yuan, "Effect of load models on assessment of energy losses in distributed generation planning", Elect., Power and Energy Systems 33, pp.1243-1250, 2011.

[13]. M. Chakravorty, D. Das, "Voltage stability analysis of radial distribution networks", Electrical Power and Energy Systems 23, pp.129-135, 2001.

[14]. R. Ranjan, B. Venkatesh and D. Das, "Voltage Stability Analysis of Radial Distribution Networks", Elect. Power Comp. and Syst., 31, pp. 501-511, 2003. 
[15]. D. Thukaram, H.M.W. Banda, and J. Jerome, "A robust three-phase power flow algorithm for radial distribution systems", Electric Power Systems Research 50, pp. 227 236, 1999.

[16]. D. Karaboga, and B. Basturk, "On the performance of artificial bee colony (ABC) algorithm”, Applied Soft Computing 8, pp. 687-697, 2008.

[17]. D. Karaboga, and B. Basturk, "A powerful and efficient algorithm for numerical function optimization: artificial bee colony (ABC) algorithm", Journal of Global Optimization 39, pp. 459-471, 2007.

[18]. D. Karaboga, and B. Akay, "A comparative study of Artificial Bee Colony algorithm”, Applied Maths., and Comput., 214, pp. 108-132, 2009.

[19]. D. Karaboga, and B. Akay, "A modified Artificial Bee Colony (ABC) algorithm for constrained optimization problems", Applied Soft Computing 11, pp. 3021-3031, 2011.

[20]. B. Akay, and D. Karaboga, "A modified Artificial Bee Colony for real-parameter optimization", Information Sciences 192, pp. 120-142, 2012.

[21]. B. Liu, L. Wang, Y. Jin, F. Tang and D. Huang, "Improved particle swarm optimization combined with chaos", chaos solutions and fractals 25, pp. 1261-1271, 2005.

[22]. N. C. Sahoo and K. Prasad, "A fuzzy genetic approach for network reconfiguration to enhance voltage stability in radial distribution systems", Energy Conv. and Managt., 47, pp. 3288-3306, 2006.

\section{Appendix}

Line and load data for 69-radial distribution system

\begin{tabular}{|c|c|c|c|c|c|}
\hline $\mathrm{F}$ & $\mathrm{T}$ & R (p.u.) & X (p.u.) & $\mathrm{P}(\mathrm{MW})$ & $\mathrm{Q}$ (MVAr) \\
\hline 1 & 2 & 0.0003 & 0.0007 & 0 & 0 \\
\hline 2 & 3 & 0.0003 & 0.0007 & 0 & 0 \\
\hline 3 & 4 & 0.0009 & 0.0022 & 0 & 0 \\
\hline 4 & 5 & 0.0157 & 0.0183 & 0 & 0 \\
\hline 5 & 6 & 0.2284 & 0.1163 & 0.0026 & 0.0022 \\
\hline 6 & 7 & 0.2378 & 0.1211 & 0.0404 & 0.0300 \\
\hline 7 & 8 & 0.0575 & 0.0293 & 0.0750 & 0.0540 \\
\hline 8 & 9 & 0.0308 & 0.0157 & 0.0300 & 0.0220 \\
\hline 9 & 10 & 0.5110 & 0.1689 & 0.0280 & 0.0190 \\
\hline 10 & 11 & 0.1168 & 0.0386 & 0.1450 & 0.1040 \\
\hline 11 & 12 & 0.4438 & 0.1467 & 0.1450 & 0.1040 \\
\hline 12 & 13 & 0.6426 & 0.2121 & 0.0080 & 0.0055 \\
\hline 13 & 14 & 0.6514 & 0.2152 & 0.0080 & 0.0055 \\
\hline 14 & 15 & 0.6601 & 0.2181 & 0 & 0 \\
\hline 15 & 16 & 0.1227 & 0.0406 & 0.0455 & 0.0300 \\
\hline 16 & 17 & 0.2336 & 0.0772 & 0.0600 & 0.0350 \\
\hline 17 & 18 & 0.0029 & 0.0010 & 0.0600 & 0.0350 \\
\hline 18 & 19 & 0.2044 & 0.0676 & 0 & 0 \\
\hline 19 & 20 & 0.1314 & 0.0434 & 0.0010 & 0.0006 \\
\hline 20 & 21 & 0.2131 & 0.0704 & 0.1140 & 0.0810 \\
\hline 21 & 22 & 0.0087 & 0.0029 & 0.0053 & 0.0035 \\
\hline 22 & 23 & 0.0993 & 0.0328 & 0 & 0 \\
\hline 23 & 24 & 0.2161 & 0.0714 & 0.0280 & 0.0200 \\
\hline 24 & 25 & 0.4672 & 0.1544 & 0 & 0 \\
\hline 25 & 26 & 0.1927 & 0.0637 & 0.0140 & 0.0100 \\
\hline 26 & 27 & 0.1081 & 0.0357 & 0.0140 & 0.0100 \\
\hline 3 & 28 & 0.0027 & 0.0067 & 0.0260 & 0.0185 \\
\hline 28 & 29 & 0.0399 & 0.0976 & 0.0260 & 0.0185 \\
\hline 29 & 30 & 0.2482 & 0.0820 & 0 & 0 \\
\hline 30 & 31 & 0.0438 & 0.0145 & 0 & 0 \\
\hline 31 & 32 & 0.2190 & 0.0724 & 0 & 0 \\
\hline 32 & 33 & 0.5235 & 0.1757 & 0.0140 & 0.0100 \\
\hline 33 & 34 & 1.0656 & 0.3523 & 0.0195 & 0.0140 \\
\hline 34 & 35 & 0.9196 & 0.3040 & 0.0060 & 0.0040 \\
\hline 3 & 36 & 0.0027 & 0.0067 & 0.0260 & 0.0186 \\
\hline 36 & 37 & 0.0399 & 0.0976 & 0.0260 & 0.0186 \\
\hline 37 & 38 & 0.0657 & 0.0767 & 0 & 0 \\
\hline
\end{tabular}




\begin{tabular}{|c|c|c|c|c|c|}
\hline 38 & 39 & 0.0190 & 0.0221 & 0.0240 & 0.0170 \\
\hline 39 & 40 & 0.0011 & 0.0013 & 0.0240 & 0.0170 \\
\hline 40 & 41 & 0.4544 & 0.5309 & 0.0012 & 0.0010 \\
\hline 41 & 42 & 0.1934 & 0.2260 & 0 & 0 \\
\hline 42 & 43 & 0.0256 & 0.0298 & 0.0060 & 0.0043 \\
\hline 43 & 44 & 0.0057 & 0.0072 & 0 & 0 \\
\hline 44 & 45 & 0.0679 & 0.0857 & 0.0392 & 0.0263 \\
\hline 45 & 46 & 0.0006 & 0.0007 & 0.0392 & 0.0263 \\
\hline 4 & 47 & 0.0021 & 0.0052 & 0 & 0 \\
\hline 47 & 48 & 0.0531 & 0.1300 & 0.0790 & 0.0564 \\
\hline 48 & 49 & 0.1808 & 0.4424 & 0.3847 & 0.2745 \\
\hline 49 & 50 & 0.0513 & 0.1255 & 0.3847 & 0.2745 \\
\hline 8 & 51 & 0.0579 & 0.0295 & 0.0405 & 0.0283 \\
\hline 51 & 52 & 0.2071 & 0.0695 & 0.0036 & 0.0027 \\
\hline 9 & 53 & 0.1086 & 0.0553 & 0.0043 & 0.0035 \\
\hline 53 & 54 & 0.1267 & 0.0645 & 0.0264 & 0.0190 \\
\hline 54 & 55 & 0.1773 & 0.0903 & 0.0240 & 0.0172 \\
\hline 55 & 56 & 0.1755 & 0.0894 & 0 & 0 \\
\hline 56 & 57 & 0.9920 & 0.3330 & 0 & 0 \\
\hline 57 & 58 & 0.4890 & 0.1641 & 0 & 0 \\
\hline 58 & 59 & 0.1898 & 0.0628 & 0.1 & 0.0720 \\
\hline 59 & 60 & 0.2409 & 0.0731 & 0 & 0 \\
\hline 60 & 61 & 0.3166 & 0.1613 & 1.2440 & 0.8880 \\
\hline 61 & 62 & 0.0608 & 0.0309 & 0.0320 & 0.0230 \\
\hline 62 & 63 & 0.0905 & 0.0460 & 0 & 0 \\
\hline 63 & 64 & 0.4433 & 0.2258 & 0.2270 & 0.1620 \\
\hline 64 & 65 & 0.6495 & 0.3308 & 0.0590 & 0.0420 \\
\hline 11 & 66 & 0.1255 & 0.0381 & 0.0180 & 0.0130 \\
\hline 66 & 67 & 0.0029 & 0.0009 & 0.0180 & 0.0130 \\
\hline 12 & 68 & 0.4613 & 0.1525 & 0.0280 & 0.0200 \\
\hline 68 & 69 & 0.0029 & 0.0010 & 0.0280 & 0.0200 \\
\hline
\end{tabular}
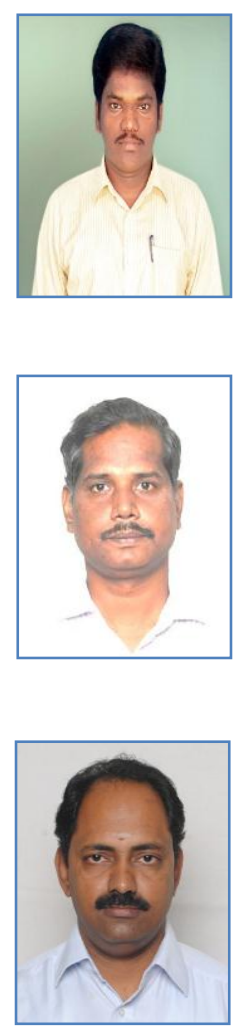

Mohandas Natarajan, He received the B.E degree in Electrical and Electronics from Madras University and M.E degree in Power Systems from Annamalai University, India in 2002 and 2008, respectively. He is working towards his Ph.D. in the area of Voltage stability analysis. His areas of interest include network loss minimization, distributed generation and application of soft computing techniques in power system engineering. He is presently an Assistant Professor in Electrical engineering, Annamalai University, Annamalai Nagar, Tamilnadu, India.

R. Balamurugan, He received his B.E. in Electrical and Electronics Engineering, M.E. in power System and Ph.D in Electrical Engineering, from Annamalai University, India in 1994, 1997 and 2008 respectively. His areas of interest include Digital Simulations of Power Systems, Control Systems, Applications of Computational Intelligence Techniques in Power System Engineering, and Electrical Machines. He is presently an Assistant Professor in Electrical Engineering, Annamalai University, Annamalai Nagar, Tamilnadu, India.

L. Lakshminarasimman, He received his B.E. in Electrical and Electronics Engineering, M.E. in Power System and $\mathrm{PhD}$ in Electrical Engineering, from Annamalai University, India in 1993, 1999 and 2008 respectively. He is presently an Associate Professor in Electrical Engineering, Annamalai University, Annamalai Nagar, Tamilnadu, India. His research interests include power system analysis, power system economics and application of computational intelligence techniques to power system optimization problems. He is a member of IEEE and a life member of Indian Society for

Technical Education. 